\title{
Spatio-temporal variability of binary weather patterns and precipitation amounts of short time intervals during winter period over the north-west Himalaya (NWH)
}

\author{
Dan Singh $^{1, *}$, Ashavani Kumar ${ }^{2}$ and M S Shekhar ${ }^{1}$ \\ ${ }^{1}$ Research and Development Centre, Snow and Avalanche Study Establishment, Sector 37 A, \\ Chandigarh 160 036, India. \\ ${ }^{2}$ Department of Physics, National Institute of Technology Kurukshetra, Kurukshetra, India. \\ ${ }^{*}$ Corresponding author.e-mail: dan_@rediffmail.com
}

MS received 18 August 2018; revised 22 April 2019; accepted 26 April 2019

Spatio-temporal variability of binary weather patterns (precipitation event/no-precipitation event) and precipitation amounts of short time intervals of 15, 24, 48 and 72 hours (h) are examined by analysing data on the observed precipitation amount of 3377 common days of different winters (winter 1993-winter 2015) at 12 stations in the north-west Himalaya (NWH). Surface meteorological variables over the NWH are collected daily at 0300 and 1200 UTC and data on the precipitation amount collected daily at 0300 UTC are taken to conduct this study. Data on the precipitation amount collected at 0300 UTC daily represent the cumulative precipitation amount of a short time interval of the previous $15 \mathrm{~h}$ (1200-0300 UTC) hence the precipitation amount of the $15 \mathrm{~h}$ time interval is considered in addition to the precipitation amounts of 24 , 48 and $72 \mathrm{~h}$ time intervals to examine the Spatio-temporal variability of the precipitation amounts at 12 stations over the NWH. The spatio-temporal variability in the binary weather patterns of short time intervals is examined by computing the normalised percentage differences in the observed precipitation events of short time intervals at 11 stations from corresponding observed precipitation events at a reference station and Spatio-temporal variability in the precipitation amount of short time interval at 12 stations is examined by computing Mean Absolute Differences (MADs) and Root Mean Square Differences (RMSDs) of observed precipitation amounts of short time intervals at each station from corresponding observed precipitation amounts at a reference station. Normalised percentage difference in precipitation events and MAD (RMSD) of the precipitation amount of $24 \mathrm{~h}$ time intervals at 11 stations from a reference station fall in the range $(-) 50.0 \%-(+) 20.7 \%$ and $4.2-7.2 \mathrm{~mm}(12.2-18.5 \mathrm{~mm})$, respectively. The maximum difference in binary weather patterns is found for $24 \mathrm{~h}$ time interval and simultaneous precipitation events are not found up to $72 \mathrm{~h}$ time interval at 12 stations over the NWH. The spatial variability of binary weather patterns is found to decrease and the spatial variability of the precipitation amount is found to increase with the increasing length of short time intervals, i.e., 15-72 h. These findings show that binary weather patterns and precipitation amounts of short time intervals exhibit large Spatio-temporal variability over the NWH. Results of this study can be useful for various applications directly (or indirectly) influenced by weather and/or precipitation amounts of short time intervals over the NWH during the winter period.

Keywords. Weather; weather forecasting; spatial variability and north-west Himalaya. 


\section{Introduction}

Precipitation primarily in solid form, i.e., snowfall, during the winter period (November-April) over the Himalaya $(\mathrm{H}) /$ north-west Himalaya (NWH) feeds glaciers and builds extensive seasonal snow cover (Dimri and Mohanty 1999; Lang and Barros 2004; Dimri and Das 2006; Srivastava 2006; Singh et al. 2015, 2016; Negi et al. 2018). Snow melt runoff from seasonal snow cover and Himalayan glaciers during spring and/or summer seasons significantly contribute to the major rivers originating from the $\mathrm{H}$ and hence largely influences various socio-economic developments in the Indian subcontinent (Archer and Fowler 2004; Fowler and Archer 2005; Arora et al. 2006; Bhutiyani et al. 2008). However, heavy snowfall during the winter period over the $\mathrm{H} / \mathrm{NWH}$ also causes many weather generated natural hazards such as severe cold temperatures, avalanches, landslides, etc. (Rangachary and Bandyopadhyay 1987; Das et al. 2003; Hatwar et al. 2005; Singh and Ganju 2005; Srinivasan et al. 2005; Joshi and Srivastava 2014). Therefore, an insight and understanding of Spatiotemporal variability of weather patterns and precipitation amount over the $\mathrm{H} / \mathrm{NWH}$ at different temporal resolutions are important for many applications influenced by weather and climate such as planning day-to-day activities, reservoir operations, operational weather forecasting, flood forecasting, hydrological modelling and applications and management of water resources, etc.(Rangachary and Bandyopadhyay 1987; Fowler and Archer 2005; Arora et al. 2006; Das et al. 2006; Bhutiyani et al. 2008).

Few studies have been conducted in the recent past to understand the spatial and/or temporal variability of the precipitation amount at a seasonal scale over the NWH (Dimri and Das 2006, 2011; Bhutiyani et al. 2008, 2009; Shekhar et al. 2010; Singh et al. 2015; Negi et al. 2018). Such studies provide an insight and understanding of the spatial and/or temporal variability of the precipitation amount at a seasonal scale over the NWH. However, the Spatio-temporal variability of weather patterns and precipitation amounts of short time intervals of 15 hours (15 h), 24, 48 and $72 \mathrm{~h}$ (hereafter $15-72 \mathrm{~h}$ ) are lacking over the NWH. An insight and understanding of the Spatiotemporal variability of weather patterns and precipitation amounts of short time intervals are of utmost importance and this study is taken to gain an insight into and an understanding of the
Spatio-temporal variability of precipitation amounts of short time intervals (15-72 h) at 12 stations over the NWH. However, this study is not intended to represent a long-term trend in the precipitation amounts of short time intervals from the point of view of climatic changes, rather it is intended to gain an insight into the Spatio-temporal variability of the precipitation amounts of short time intervals from the point of view of short range weather and precipitation variability over the NWH. Precipitation amounts of short time intervals $(15-72 \mathrm{~h})$ are taken as per the availability of daily meteorological observations and majority of snow storms of $72 \mathrm{~h}$ time interval over the NWH (Dimri and Mohanty 1999; Srivastava 2006). Reasons for choosing the winter period for this study are the availability of surface meteorological observations and prime importance of weather and quantitative precipitation amount forecasting during the winter period over the NWH.

\section{Data used}

Data on the precipitation amount of short time intervals $(15-72 \mathrm{~h})$ at 12 stations in the $\mathrm{NWH}$ are analysed (figure 1). Observations on the snowfall amount and rainfall amount collected daily at 0300 and 1200 UTC are obtained from the data archive of the Snow and Avalanche Study Establishment (SASE), India (Bhutiyani et al. 2009; Dimri and Das 2011; Singh et al. 2015). Daily data collected at 0300 and 1200 UTC on snowfall (rainfall) amount represent the cumulative snowfall (rainfall) amount of the past 15 hours time interval $(15 \mathrm{~h})$ (1200-0300 UTC) and past $9 \mathrm{~h}$ time interval (0300-1200 UTC), respectively. Cumulative snowfall (rainfall) amounts of the past $24 \mathrm{~h}$, past $48 \mathrm{~h}$ and past $72 \mathrm{~h}$ time intervals are computed utilising data collected on snowfall (rainfall) amounts at 0300 and 1200 UTC at each station. Uniform snow density equal to $100 \mathrm{~kg} \mathrm{~m}^{-3}$ is assumed to change snowfall amounts of $15,24,48$ and $72 \mathrm{~h}$ time intervals into snow water equivalents of $15,24,48$ and $72 \mathrm{~h}$ time intervals. Uniform snow density equal to $100 \mathrm{~kg} \mathrm{~m}^{-3}$ is assumed due to the unavailability of snow density at a few stations over the NWH. Snow water equivalents of 15,24 , 48 and $72 \mathrm{~h}$ time intervals are aggregated with the rainfall amounts of 15, 24, 48 and $72 \mathrm{~h}$ time intervals, respectively, to compute precipitation amounts of 15, 24, 48 and $72 \mathrm{~h}$ time intervals. Data on the precipitation amount collected at 0300 UTC 


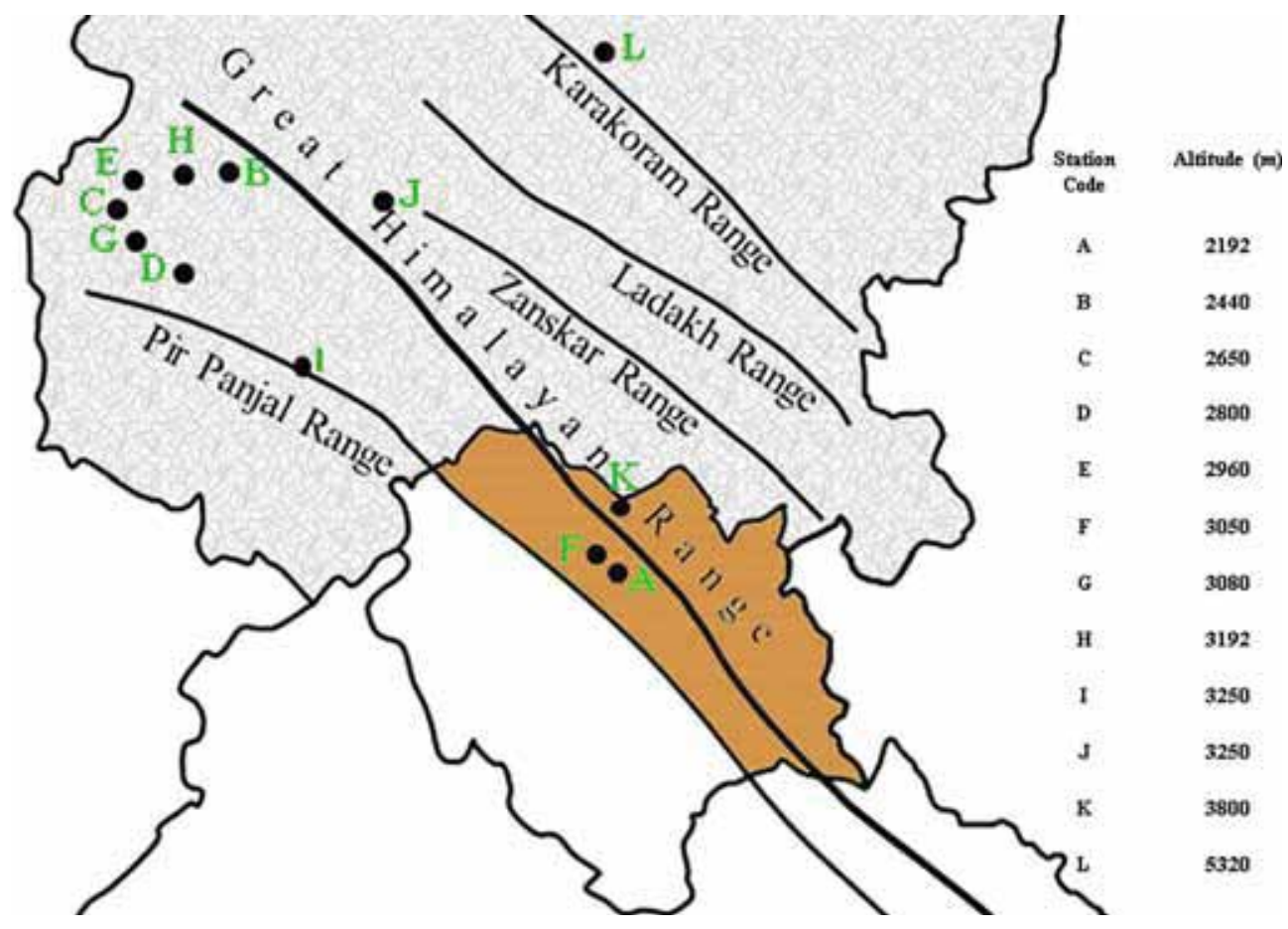

Figure 1. Stations falling under different mountain ranges over the NWH.

Table 1. Total number of precipitation events, mean precipitation amounts and standard deviations of precipitation amounts of 15, 24, 48 and $72 \mathrm{~h}$ time intervals at 12 stations over the $N W H(\mu=$ mean, $\Omega=$ standard deviation, $S$ range $=$ The Shamshawari range, $P$ range $=$ The Pir Panjal range, $G$ range $=$ The Great Himalaya range, $K$ range $=$ The Karakoram range).

\begin{tabular}{|c|c|c|c|c|c|c|c|c|c|c|c|c|c|}
\hline \multirow{3}{*}{$\begin{array}{l}\text { Mountain } \\
\text { range }\end{array}$} & \multirow[b]{3}{*}{ Station } & \multirow{2}{*}{\multicolumn{4}{|c|}{ Precipitation events }} & \multicolumn{8}{|c|}{ Precipitation amount } \\
\hline & & & & & & \multicolumn{2}{|c|}{$15 \mathrm{~h}$} & \multicolumn{2}{|c|}{$24 \mathrm{~h}$} & \multicolumn{2}{|c|}{$48 \mathrm{~h}$} & \multicolumn{2}{|c|}{$72 \mathrm{~h}$} \\
\hline & & $15 \mathrm{~h}$ & $24 \mathrm{~h}$ & $48 \mathrm{~h}$ & $72 \mathrm{~h}$ & $\mu$ & $\Omega$ & $\mu$ & $\Omega$ & $\mu$ & $\Omega$ & $\mu$ & $\Omega$ \\
\hline \multirow[t]{3}{*}{$S$ range } & $\mathrm{C}$ & 969 & 1209 & 1637 & 1959 & 14.5 & 14.7 & 19.3 & 20.5 & 28.7 & 31.3 & 36.1 & 38.9 \\
\hline & $\mathrm{E}$ & 939 & 1138 & 1568 & 1894 & 13.6 & 13.8 & 18.2 & 19.0 & 26.5 & 29.1 & 33.0 & 36.2 \\
\hline & $\mathrm{H}$ & 972 & 1157 & 1587 & 1910 & 12.5 & 12.1 & 17.2 & 17.9 & 25.2 & 27.3 & 31.5 & 34.3 \\
\hline \multirow[t]{5}{*}{$\mathrm{P}$ range } & $\mathrm{A}$ & 685 & 831 & 1190 & 1482 & 12.4 & 13.3 & 15.9 & 17.6 & 22.0 & 25.1 & 26.5 & 29.7 \\
\hline & $\mathrm{F}$ & 792 & 968 & 1363 & 1673 & 17.9 & 19.5 & 24.3 & 27.5 & 34.5 & 41.1 & 42.4 & 50.4 \\
\hline & $\mathrm{D}$ & 847 & 1084 & 1522 & 1851 & 11.7 & 12.4 & 15.3 & 17.1 & 21.8 & 25.2 & 27.0 & 31.0 \\
\hline & $\mathrm{G}$ & 920 & 1167 & 1605 & 1925 & 12.8 & 12.8 & 17.0 & 17.2 & 24.7 & 26.0 & 31.0 & 32.2 \\
\hline & I & 627 & 767 & 1122 & 1408 & 13.3 & 20.2 & 18.8 & 26.8 & 25.7 & 36.6 & 30.8 & 42.7 \\
\hline \multirow[t]{3}{*}{$\mathrm{G}$ range } & $\mathrm{K}$ & 732 & 871 & 1303 & 1625 & 7.7 & 8.0 & 8.3 & 10.7 & 11.4 & 15.1 & 13.8 & 18.1 \\
\hline & B & 1109 & 1270 & 1713 & 2035 & 12.5 & 11.6 & 16.6 & 16.4 & 24.6 & 25.1 & 31.2 & 29.7 \\
\hline & $\mathrm{J}$ & 758 & 876 & 1285 & 1616 & 6.6 & 6.7 & 8.3 & 8.9 & 11.4 & 12.6 & 13.8 & 15.3 \\
\hline $\mathrm{K}$ range & $\mathrm{L}$ & 1134 & 1457 & 1956 & 2300 & 3.3 & 2.9 & 4.5 & 4.4 & 6.6 & 7.1 & 8.4 & 9.2 \\
\hline
\end{tabular}

are analysed to conduct this study which consist of precipitation amounts of short time interval of $15 \mathrm{~h}$ (highest temporal resolution of observed precipitation amount at 0300 UTC), 24, 48 and $72 \mathrm{~h}$.

Surface meteorological observations over the NWH are spatially and temporally inhomogeneous (Dimri and Das 2011; Singh et al. 2015). Therefore, a data base of 3377 common days of different winters (winter 1993-winter 2015) at 12 stations in the NWH is prepared and utilised in this study. The total number of precipitation events, means and standard deviations of precipitation amounts of $15,24,48$ and $72 \mathrm{~h}$ time intervals at 12 stations are given in table 1. Large differences in precipitation events and mean precipitation amounts of short time intervals at 12 stations suggest that binary weather patterns and precipitation amounts 
of short time intervals exhibit large Spatio-temporal variability over the NWH (table 1).

\section{Data analysis}

Pearson correlation coefficients (CCs) between precipitation amounts of short time intervals $(15-72 \mathrm{~h})$ at 12 stations in the NWH were computed to gain an insight into whether precipitation amounts of short time intervals follow similar (linear) trends at 12 stations over the NWH. CCs can provide an idea on whether precipitation amounts of short time intervals at 12 stations follow similar (linear) trend in an overall statistical sense. However, CCs do not provide any estimate of Spatio-temporal variability of binary weather patterns and precipitation amounts of short time intervals at 12 stations over the NWH, i.e., differences in precipitation events and precipitation amounts of short time intervals at 12 stations in the NWH. Differences in precipitation events of short time intervals $(15-72 \mathrm{~h})$ at 12 stations can provide an insight into and an understanding of Spatio-temporal variability of binary weather patterns (precipitation event/no precipitation event) and differences in precipitation amounts of short time intervals at 12 stations can provide estimates of Spatio-temporal variability of precipitation amounts of short time intervals at 12 stations over the NWH. Normalised percentage differences in the precipitation events of short time intervals at 11 stations from a reference station, F, are computed to examine the Spatio-temporal variability of binary weather patterns at 12 stations over the NWH (figure 1). Normalised percentage differences in binary weather patterns of short time intervals $(15-72 \mathrm{~h})$ at each station from a reference station, $\mathrm{F}$, are computed using the following expression.

$$
\mathrm{DPT}_{j t}=100 \times\left(\frac{\mathrm{PT}_{r t}-\mathrm{PT}_{j t}}{\mathrm{PT}_{r t}}\right) \%,
$$

where $\mathrm{DPT}_{j t}$ is the normalised percentage difference in precipitation events at a station, $j$, for time interval $t, j=1$ to 12 (number of stations), $t=15$, 24, 48 and $72 \mathrm{~h}$ (time intervals); $\mathrm{PT}_{r t}$ is the total number of precipitation events at a reference station, $\mathrm{F}$ and $\mathrm{PT}_{j t}$ is the total number of precipitation events at a station, $j$, for time interval $t$.

Differences in precipitation events provide an idea on the Spatio-temporal variability of binary weather patterns of short time intervals at 12 stations in the NWH. However, such differences do not provide any idea and insight into the Spatiotemporal variability of the precipitation amounts of short time intervals at 12 stations in the NWH. Mean Absolute Differences (MADs) and Root Mean Square Differences (RMSDs) in precipitation amounts of short time intervals at each station from a reference station, F, are computed to get an idea on the Spatio-temporal variability of precipitation amounts of short time intervals at 12 stations over the NWH. MADs and RMSDs of precipitation amounts of short time intervals at any station from a reference station, F, are computed using the following expression.

$$
\begin{aligned}
\operatorname{MADPT}_{j t} & =\frac{1}{n} \sum_{i=1}^{n} \operatorname{abs}\left(\mathrm{AMPT}_{i, r t}-\mathrm{AMPT}_{i, j t}\right), \\
\mathrm{RMSDPT}_{j t} & =\sqrt{\frac{1}{n} \sum_{i=1}^{n}\left(\mathrm{AMPT}_{i, r t}-\mathrm{AMPT}_{i, j t}\right)^{2}},
\end{aligned}
$$

where $\mathrm{MADPT}_{j t}$ and $\mathrm{RMSDPT}_{j t}$ are the MAD and RMSD in the precipitation amount at a station, $j$, from the precipitation amount at a reference station, $\mathrm{F}$, for time interval $t . \mathrm{AMPT}_{i, j t}$ and $\mathrm{AMPT}_{i, r t}$ are precipitation amounts at a station, $j$, and precipitation amount at a reference station, $\mathrm{F}$, for time interval $t$ and for day $i$ ( $i=1$ to $n, n$ is total number of observations).

MADs and RMSDs provide an estimate of Spatio-temporal variability of precipitation amounts of short time intervals between reference station, F, and 11 other stations in the NWH. However, MADs (RMSDs) can not provide an idea on whether precipitation amounts of short time intervals at a reference station, F, over (under) estimate precipitation amounts of short time intervals at any other station in the NWH. Bias (BIAS) is computed to gain an insight into the over (under) estimation of the precipitation amount at any other station by precipitation amount at a reference station, $\mathrm{F}$, and it is computed using expression (4).

$$
\mathrm{BIASPT}_{j t}=\mathrm{MPT}_{r t}-\mathrm{MPT}_{j t},
$$

where BIASPT $_{j t}$ is bias in precipitation amount at a station, $j$, for time interval $t, \mathrm{MPT}_{r t}$ and $\mathrm{MPT}_{j t}$ are mean precipitation amount at a reference station, $\mathrm{F}$ and mean precipitation amount at a station, $j$, for time interval $t$. 


\section{Results and discussion}

Data on the observed precipitation amount of 3377 common days of different winters (winter 1993winter 2015) at 12 stations in the NWH were analysed to examine the Spatio-temporal variability of binary weather patterns and precipitation amounts of short time intervals over the NWH. Pearson Correlation Coefficients (CCs) between precipitation amounts of short time intervals at 12 stations were computed to know whether precipitation amounts of short time intervals exhibit similar (linear) trends at 12 stations in the NWH. CCs between precipitation amounts of $15,24,48$ and $72 \mathrm{~h}$ time intervals fall in the range $0.19-0.85, \quad 0.22-0.87, \quad 0.23-0.90$ and $0.24-0.90$, respectively, at 12 stations in the NWH and CCs between precipitation amounts of short time intervals at 12 stations are found to be statistically significant (table 2, significant at 1\% significance level). High values of CCs between precipitation amounts of short time intervals at 12 stations over the NWH can be attributed to the large number of no precipitation days (precipitation amount $=0.0 \mathrm{~mm}$ ). Values of CCs between precipitation amounts of short time intervals at 12 stations in the NWH increase with an increase in the length of the short time interval, i.e., 15-72 h (table 2). This suggests that the resemblance (similarity) in trends of the precipitation amount of the short time intervals between 12 stations is enhanced as the length of short time interval increases, i.e., precipitation (no precipitation) at one station is generally followed by precipitation (no precipitation) at another station(s) with the increase in the length of the short time interval (table 2). Precipitation amounts of short time intervals at a station, A, exhibit the highest CCs with the precipitation amounts of short time intervals at stations, F and K, which fall within the similar geographic region of the NWH (table 2, figure 1). Similarly, precipitation amounts of short time intervals at stations B, C, D, E, G, H and J exhibit statistically significant high positive CCs $(>0.60)$ (table 2). High values of CCs between the precipitation amounts of short time intervals for stations falling within the similar geographic areas in the NWH can be attributed to the movement of the Western disturbances (WDs) over the NWH (table 2, figure 1). However, the precipitation amounts of short time intervals at a station $\mathrm{L}$ exhibit the lowest values of CCs with precipitation amounts of short time intervals at the other 11 stations over the NWH (table 2). CCs provide an idea that the precipitation amounts of short time intervals at 12 stations in the NWH exhibit similar (linear) trends in the overall statistical sense. However, CCs do not provide an insight into and an understanding of the Spatio-temporal variability of the precipitation amounts of short time intervals at 12 stations in the NWH, i.e., estimates of differences in precipitation amounts of short time intervals at 12 stations in the NWH. Therefore, normalised percentage differences in binary weather patterns and MADs and RMSDs in precipitation amounts of short time intervals at 11 stations from a reference station, $\mathrm{F}$, are utilised to examine the Spatio-temporal variability of binary weather patterns and precipitation amounts of short time intervals at 12 stations in the NWH.

Normalised percentage differences in precipitation events of short time intervals, MADs, RMSDs and biases of precipitation amounts of short time intervals at 11 stations from a reference station, $\mathrm{F}$, are computed. Positive (negative) values of normalised percentage differences in precipitation events of short time intervals at any station from a reference station, $\mathrm{F}$, show that the reference station, F, has more (less) precipitation events compared to that station. Large positive (negative) values are found for normalised percentage differences in precipitation events between a reference station, F, and the other 11 stations over the NWH (figure 2). Normalised percentage differences in precipitation events between a reference station, F, and the other 11 stations were found to fall in the range (-) $43.2 \%-(+) 20.8 \%,(-) 50.5 \%-(+) 20.8 \%$, (-) $43.5 \%-(+) 17.7 \%$ and $(-) 37.5 \%-(+) 15.8 \%$ for $15,24,48$ and $72 \mathrm{~h}$ time intervals, respectively (figure 2). Normalised percentage differences in precipitation events between a reference station, $\mathrm{F}$, and the other 11 stations over the NWH were found to be maximum for precipitation events of 24 $\mathrm{h}$ time interval (a day) (figure 2). Normalised percentage differences in precipitation events of short time intervals (15-72 h) at each station from precipitation events at a reference station, $\mathrm{F}$, were found to decrease with the increase in length of a short time interval beyond 24 h, i.e., $24-72 \mathrm{~h}$. This shows that the simultaneous precipitation events at different stations increase after $24 \mathrm{~h}$ of commencement of precipitation at a reference station, F (figure 2). However, more than $10 \%$ positive (negative) values of normalised percentage differences in precipitation events between a reference station, F, and most of the other stations for the $72 \mathrm{~h}$ time interval in the NWH show that precipitation does not occur simultaneously at 12 stations up to $72 \mathrm{~h}$ time interval over the NWH (figure 2). Large differences in precipitation events of $24 \mathrm{~h}$ 
Table 2. Pearson Correlation Coefficients (CCs) between precipitation amounts of short time intervals (15-72 h) at 12 stations over the NWH ( $T=$ length of the short time interval; $S=$ stations; $*$ CCs significant at $1 \%$ significance level).

\begin{tabular}{cccccccccccccc}
\hline & \multicolumn{1}{c|}{ S } & A & B & C & D & E & F & G & H & I & J & K & L \\
\hline
\end{tabular}

$T=$ Precipitation amount of $15 \mathrm{~h}$ time interval

A

B $\quad 0.40^{*}$

C $0.40^{*} \quad 0.78^{*}$

D $\quad 0.45^{*} \quad 0.78^{*} \quad 0.80^{*}$

E $\quad 0.36^{*} \quad 0.77^{*} \quad 0.85^{*} \quad 0.73^{*}$

$\begin{array}{llllll}\mathrm{F} & 0.78^{*} & 0.52^{*} & 0.53^{*} & 0.58^{*} & 0.49^{*}\end{array}$

$\begin{array}{llllll}\mathrm{G} & 0.37^{*} & 0.66^{*} & 0.79^{*} & 0.74^{*} & 0.73^{*}\end{array}$

$\mathrm{H} \quad 0.40^{*} \quad 0.80^{*} \quad 0.77^{*} \quad 0.72^{*}$

I $\quad 0.47^{*} \quad 0.53^{*} \quad 0.56^{*} \quad 0.60^{*}$

$\begin{array}{lllll}\mathrm{J} & 0.45^{*} & 0.61^{*} & 0.56^{*} & 0.59^{*}\end{array}$

$\begin{array}{lllll}\mathrm{K} & 0.67^{*} & 0.51^{*} & 0.50^{*} & 0.53^{*}\end{array}$

$\begin{array}{lllll}\mathrm{L} & 0.20^{*} & 0.31^{*} & 0.31^{*} & 0.29^{*}\end{array}$

$0.73^{*}$

$0.49^{*}$

$0.47^{*} \quad 0.59^{*}$

$0.54^{*} \quad 0.44^{*}$

$0.49^{*} \quad 0.71^{*}$

$0.51^{*} \quad 0.50^{*}$

$0.61^{*} \quad 0.41^{*}$

$\begin{array}{llll}0.45^{*} & 0.50^{*} \quad 0.49^{*} \quad 0.55^{*}\end{array}$

$\begin{array}{llllll}0.28^{*} & 0.19^{*} & 0.29^{*} & 0.31^{*} & 0.20^{*} & 0.33^{*}\end{array}$

$0.28^{*}$

$T=$ Precipitation amount of $24 \mathrm{~h}$ time interval

A

B $0.45^{*}$

C $0.45^{*} \quad 0.82^{*}$

D $\quad 0.50^{*} \quad 0.81^{*}$

$\begin{array}{lllll}\mathrm{E} & 0.45^{*} & 0.80^{*} & 0.87^{*} & 0.76^{*}\end{array}$

F $0.79^{*} \quad 0.57^{*} \quad 0.59^{*} \quad 0.62^{*}$

G $\begin{array}{lllll} & 0.47^{*} & 0.74^{*} & 0.83^{*} & 0.79^{*}\end{array}$

$\mathrm{H} \quad 0.46^{*} \quad 0.82^{*} \quad 0.80^{*} \quad 0.75^{*}$

I $\quad 0.51^{*} \quad 0.56^{*} \quad 0.57^{*} \quad 0.63^{*}$

$\begin{array}{llll}\mathrm{J} & 0.47^{*} & 0.65^{*} & 0.60^{*}\end{array}$

$\begin{array}{llll}\mathrm{K} & 0.70^{*} & 0.54^{*} & 0.55^{*}\end{array}$

$0.61^{*}$

$0.56^{*}$

$0.78^{*} \quad 0.58^{*}$

$0.82^{*} \quad 0.54^{*} \quad 0.73^{*}$

$0.49^{*} \quad 0.63^{*} \quad 0.56^{*}$

$0.60^{*} \quad 0.50^{*} \quad 0.52^{*}$

$0.53^{*}$

$0.50^{*} \quad 0.52^{*} \quad 0.65^{*}$

$0.55^{*} \quad 0.54^{*}$

$0.73^{*}$

$0.53^{*}$

$0.54^{*}$

$0.45^{*}$

$0.33 *$

$0.23^{*}$

$0.33^{*}$

$0.34^{*}$

$0.52^{*}$

$0.59^{*}$

$0.22^{*} \quad 0.37^{*}$

$0.32^{*}$

$T=$ Precipitation amount of $48 \mathrm{~h}$ time interval

A

B $0.53^{*}$

C $0.53^{*} \quad 0.86^{*}$

D $0.58^{*} \quad 0.84^{*}$

E $0.52^{*} \quad 0.84^{*}$

F $0.81^{*} \quad 0.65^{*}$

$0.86^{*}$

$0.55^{*}$

$0.65^{*} \quad 0.68^{*}$

$0.90^{*}$
$0.68^{*}$
$0.87^{*}$

$0.80^{*}$

$0.54^{*}$

$0.85 *$

$0.83^{*}$

$0.70^{*}$

$0.82^{*}$

$0.63^{*}$

$0.81^{*} \quad 0.66^{*}$

$0.78^{*} \quad 0.85^{*} \quad 0.62^{*}$

I $\quad 0.56^{*} \quad 0.62^{*}$

$0.64^{*}$

$0.68^{*}$

$0.56^{*}$

$0.69^{*}$

$0.77^{*}$

$\mathrm{J} \quad 0.54^{*}$

$0.70^{*}$

$0.65^{*}$

$0.66^{*}$

$0.66^{*}$

$0.55^{*}$

$0.63^{*}$

$0.58^{*}$

$0.58^{*}$

$\begin{array}{ll}\mathrm{K} & 0.73^{*} \\ \mathrm{~L} & 0.25^{*}\end{array}$

$0.38^{*}$

$0.63^{*}$
$0.37^{*}$

$0.63^{*}$

$0.62^{*}$

$0.76^{*}$

$0.60 *$

$0.70^{*}$

$0.24^{*}$

$0.36^{*}$

$0.62^{*}$

$0.47^{*}$

$0.55^{*} \quad 0.65^{*}$

$0.23^{*} \quad 0.41^{*}$

$0.35^{*}$

$T=$ Precipitation amount of $72 \mathrm{~h}$ time interval

A

B $0.56^{*}$

C $0.57^{*}$

D $0.61^{*} \quad 0.85^{*}$

E $0.56^{*} \quad 0.85^{*}$

F $0.82^{*} \quad 0.68^{*}$

G $\quad 0.58^{*} \quad 0.79^{*}$

$\mathrm{H} \quad 0.57^{*} \quad 0.86^{*}$

I $\quad 0.58^{*} \quad 0.64^{*}$

$0.64^{*}$

$0.87^{*}$

$0.90^{*}$

$0.71^{*}$

$0.87^{*}$

$0.74^{*}$

$0.84^{*}$

$0.83^{*}$

$0.68^{*}$

$0.80^{*}$

$0.83^{*} \quad 0.70^{*}$

$0.56^{*}$

$0.66^{*}$

$0.70^{*}$

$0.87^{*}$

$0.59^{*}$

$0.67^{*}$

$\mathrm{K} \quad 0.75^{*}$

$0.64^{*}$

$0.66^{*}$

$0.67^{*}$

$0.68^{*}$

$0.65^{*}$

$0.65^{*}$

$0.72^{*}$

$0.79^{*}$

$0.57^{*}$

$0.66^{*}$

$0.59^{*}$

$0.61^{*}$

$0.78^{*}$

$0.64^{*}$

$0.72^{*}$

$0.38^{*}$

$0.24^{*}$

$0.36^{*}$

$0.38^{*}$

$0.49^{*}$

$0.57^{*} \quad 0.67^{*}$

$0.28^{*}$

$0.42^{*}$

$0.36^{*}$ 
time interval at 11 stations from a reference station show that perfect binary weather forecasts (precipitation day/no precipitation day) for lead time up to $24 \mathrm{~h}$ at one station are likely to be the least accurate at any other station in the NWH and its binary forecast error will be equal to the percentage difference in precipitation events of the $24 \mathrm{~h}$ time interval between both the stations.

Least normalised percentage differences in precipitation events of short time intervals from precipitation events at a reference station, F, are found for stations $\mathrm{J}$ and $\mathrm{K}$ for a $24 \mathrm{~h}$ time interval (figure 2). This suggests that binary weather patterns between stations $\mathrm{F}, \mathrm{J}$ and $\mathrm{K}$ show good resemblance (figure 2). The resemblance between binary weather patterns at stations $\mathrm{F}$ and $\mathrm{K}$ are expected due to their geographic locations. However, stations B, C, D, E, G and $\mathrm{H}$ fall within an altitude difference of $0.75 \mathrm{~km}$ and distance (computed based on the latitude and longitude of stations) of $57.3 \mathrm{~km}$ (figures 1 and 2). These stations falling within similar geographic areas also exhibit large differences in precipitation events of short time intervals (figure 2). Binary weather patterns at a station $\mathrm{K}$ in the Karakoram range are found to differ largely from binary weather patterns at a reference station, F, compared to the other 10 stations in the NWH (figure 2). This can be attributed to the geographic positions of different stations and movements of the WDs over the NWH during the winter period. Differences in latitudes and longitudes of different stations (in degrees) from the latitude and longitude of a reference station, F, and distances of different stations (computed based on the latitude and longitude of different stations) from a reference station are shown in figure 2. Normalised percentage differences in precipitation events do not show any specific increasing and/or decreasing pattern with altitudes and distances of different stations from a reference station, F, over the NWH (figure 2).

Normalised percentage differences in precipitation events for stations belonging to similar geographic areas from a reference station, F, are also examined to know whether precipitation events differ for stations falling within similar geographic areas. Normalised percentage differences in precipitation events of $15,24,48$ and $72 \mathrm{~h}$ time intervals from a reference station, $\mathrm{F}$, fall in the range (-) $22.3 \%-(-) 18.6 \%$, (-) $24.9 \%-(-) 17.6 \%$, (-) $20.1 \%-(-) 15.0 \%$, and (-) $17.1-(-) 13.2 \%$ for the stations falling in the Shamshawari range, (-) $16.2 \%-(+) 20.8 \%,(-) 20.6 \%-(+) 20.8 \%$,
(-) $17.8 \%-(+) 17.7 \%$ and $(-) 15.1 \%-(+) 15.8 \%$ for the stations falling the Pir Panjal range, $(-)$ 40.0-(+) $7.6 \%,(-) 31.2 \%-(+) 10.0 \%,(-) 25.7 \%-(+) 5.7 \%$, and $(-) 21.6 \%-(+) 3.4 \%$ for the stations falling in the Great Himalaya range and (-) $43.2 \%$, (-) $50.5 \%,(-) 43.5 \%$ and (-) $37.5 \%$ for station L falling in the Karakoram range, respectively (figure 3). Normalised percentage differences in precipitation events of short time intervals from precipitation events at reference station, F, show positive (negative) values and exhibit large spatial variability for stations falling in the Pir Panjal range and the Great Himalaya range for short time intervals (figure 3). Stations $\mathrm{A}$ and $\mathrm{F}$ belong to the same geographic areas in the Pir Panjal range of the NWH at a distance of about $12.2 \mathrm{~km}$ (figure 3). Normalised percentage differences in precipitation events of short time intervals between stations A and $\mathrm{F}$ were found to fall in the range $11.4-14.2 \%$ (figure 3). This shows that stations at short distances and those falling within similar geographic areas also exhibit large spatial variability in binary weather patterns over the NWH (figure 3). However, binary weather patterns for the stations falling within the Shamshawari range (stations C, E and $\mathrm{H}$ ) are found to be more similar compared to the other areas in the NWH (figure 3).

MADs in precipitation amounts of short time intervals at 11 stations from the precipitation amount at a reference station, $\mathrm{F}$, fall in the range $2.5-4.6,4.2-7.2,8.0-13.8$ and $11.8-20.2 \mathrm{~mm}$ for $15,24,48$ and $72 \mathrm{~h}$ time intervals, respectively (figure 4). RMSDs in precipitation amounts of short time intervals at 11 stations from the precipitation amount at a reference station, F, are computed. RMSDs are more sensitive to large differences in precipitation amounts of short time intervals; hence RMSDs are computed to get an idea of the Spatio-temporal variability of the precipitation amounts of short time intervals in addition to MADs. RMSDs in the precipitation amounts of short time intervals at 11 stations from the precipitation amount at a reference station, $\mathrm{F}$, falls in the range 8.1-12.4, 12.2-18.5, $20.4-31.7$ and $27.3-42.5 \mathrm{~mm}$ for $15,24,48$ and $72 \mathrm{~h}$ time intervals, respectively (figure 5). Large differences in MADs and RMSDs between the precipitation amounts of $15,24,48$ and $72 \mathrm{~h}$ time intervals are found at each station over the NWH (figures 4 and 5). Large values of RMSDs show that there are few days for which the precipitation amount at each station differs largely from the precipitation amount at a reference station, $\mathrm{F}$. 


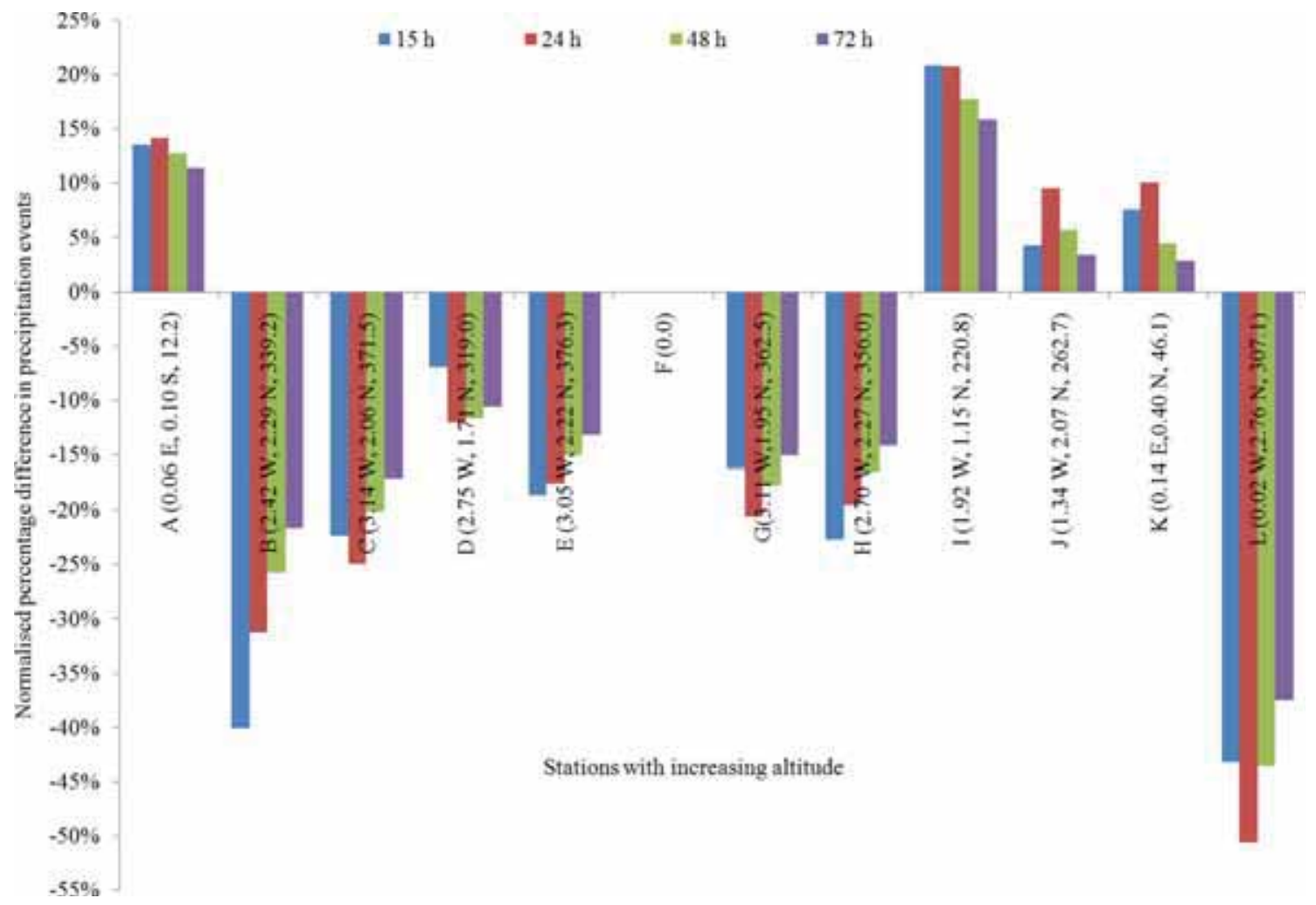

Figure 2. Normalised percentage differences in the precipitation events of short time intervals of $15,24,48$ and $72 \mathrm{~h}$ at 11 stations from a reference station, F, in the NWH. (The differences in the latitude and longitude of each station (in degrees) and distance (computed based on the latitude and longitude) of each station from a reference station, F, are shown within brackets).

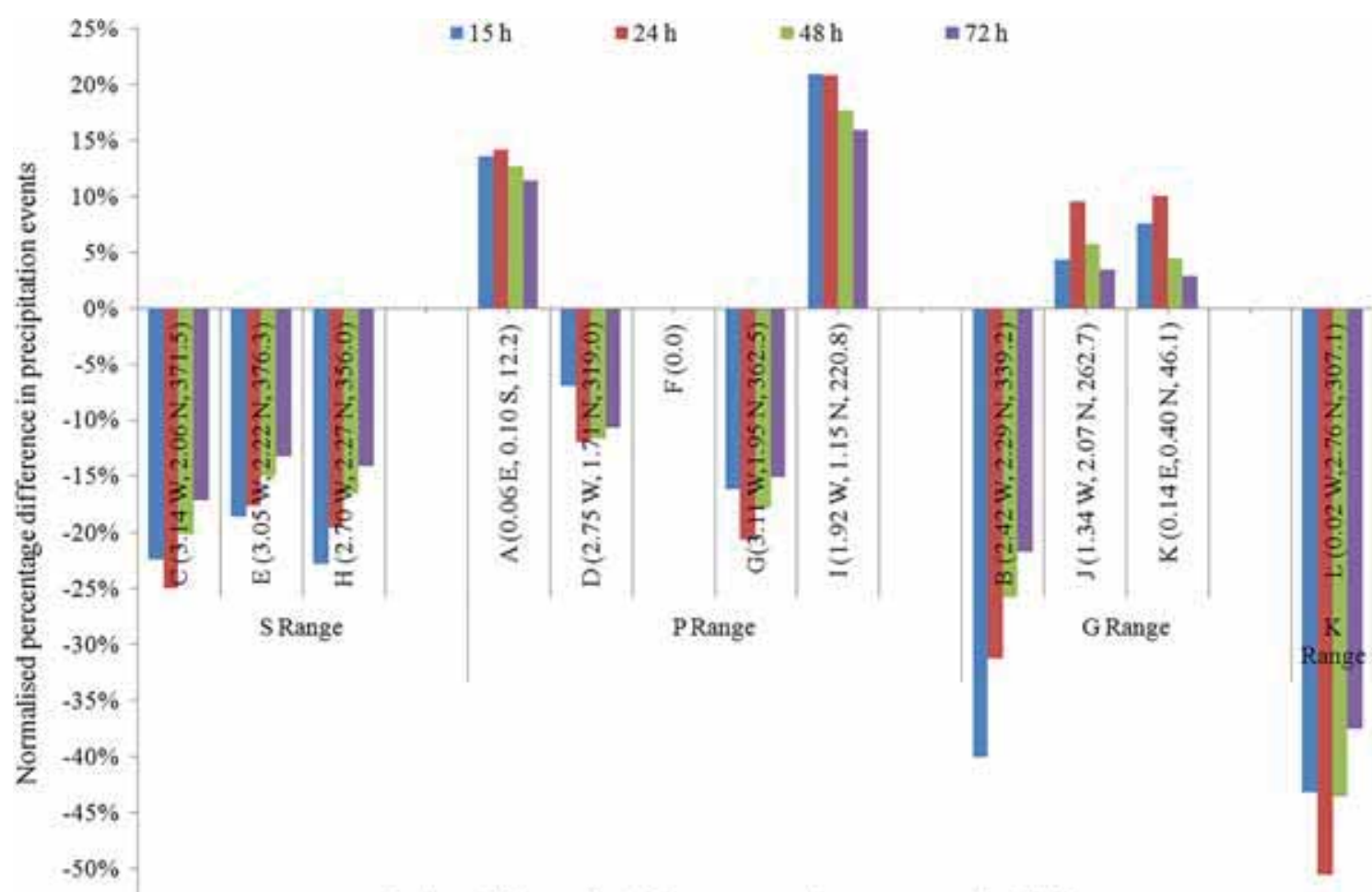

$-55 \%$

Stations falling under different mountain ranges over the NWH

Figure 3. Normalised percentage differences in the precipitation events of short time intervals (15-72 h) at 11 stations falling under different mountain ranges over the NWH from a reference station, F. (The differences in the latitude and longitude of each station (in degrees) and distance (computed based on the latitude and longitude) of each station from a reference station, F, are shown within brackets). 


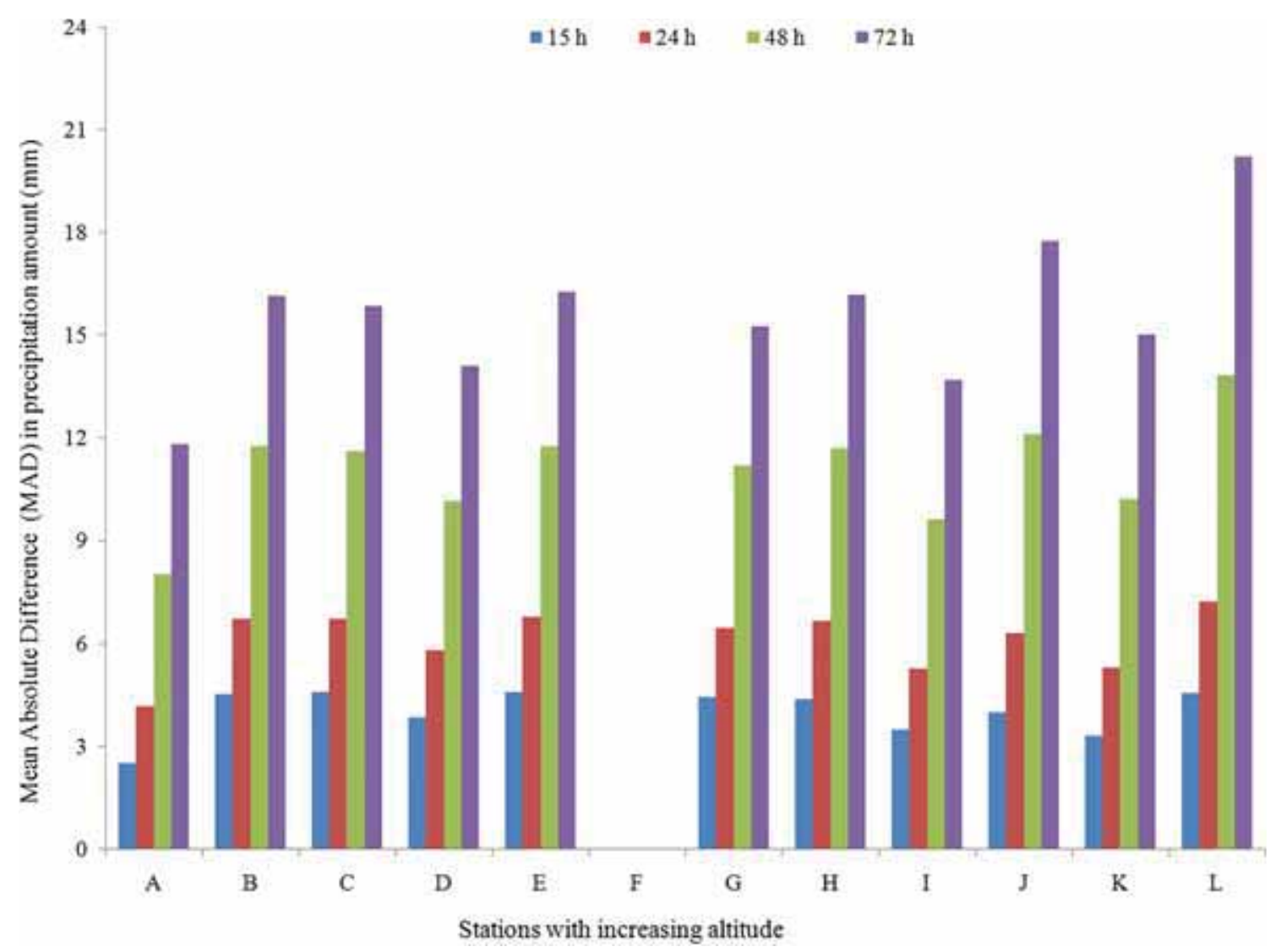

Figure 4. Mean Absolute Differences (MADs) in precipitation amounts of short time intervals (15-72 h) at 11 stations from a reference station, F, over the NWH.

MADs (RMSDs) of precipitation amounts of short time intervals at different stations from the precipitation amount at a reference station, F, are found not to show any increasing and/or decreasing pattern with respect to altitudes and distances of different stations from a reference station, $\mathrm{F}$ (figures 4 and 5).

MADs (RMSDs) of precipitation amounts of short time intervals at different stations from the precipitation amount at a reference station, F, increase with the increase in length of the short time interval, i.e., 15-72 h (figures 4 and 5). This shows that the precipitation amount of a shorter time interval $(15 \mathrm{~h})$ at a reference station, $\mathrm{F}$, can provide a better estimate of the precipitation amount at the other 11 stations compared to the precipitation amount of a longer time interval (more than $15 \mathrm{~h}$ ) over the NWH (figure 4). MADs (RMSDs) of precipitation amounts of a short time interval are found to exhibit large temporal variability at each station, especially for the 48 and 72 $\mathrm{h}$ time intervals. MADs (RMSDs) of precipitation amounts of short time intervals at 11 stations from the precipitation amount at a reference station, F, are found to increase while the observed precipitation events of short time intervals at different stations from the observed precipitation events at a reference station, F, are found to decrease with the increasing length of short time intervals (figures 2, 4 and 5). This shows that the error growth in precipitation events decreases while the error growth in the precipitation amount increases at 11 stations from the precipitation events and precipitation amounts of short time intervals at a reference station, $\mathrm{F}$, with the increase in the length of the short time interval, i.e., 24-72 $\mathrm{h}$, over the NWH. Large values of MADs (RMSDs) of precipitation amount at 11 stations and large differences in MADs (RMSDs) of precipitation amount at each station for short time intervals show that precipitation amount exhibits large Spatio-temporal variability over the NWH. MADs (RMSDs) of precipitation amounts of short time intervals at 11 stations represent Mean Absolute Errors (MAEs) (Root Mean Square Errors (RMSEs)) of a perfect quantitative precipitation forecast model at a reference station, F, over the NWH. These results indicate challenges of short range binary weather forecasting and quantitative precipitation forecasting over the NWH and 


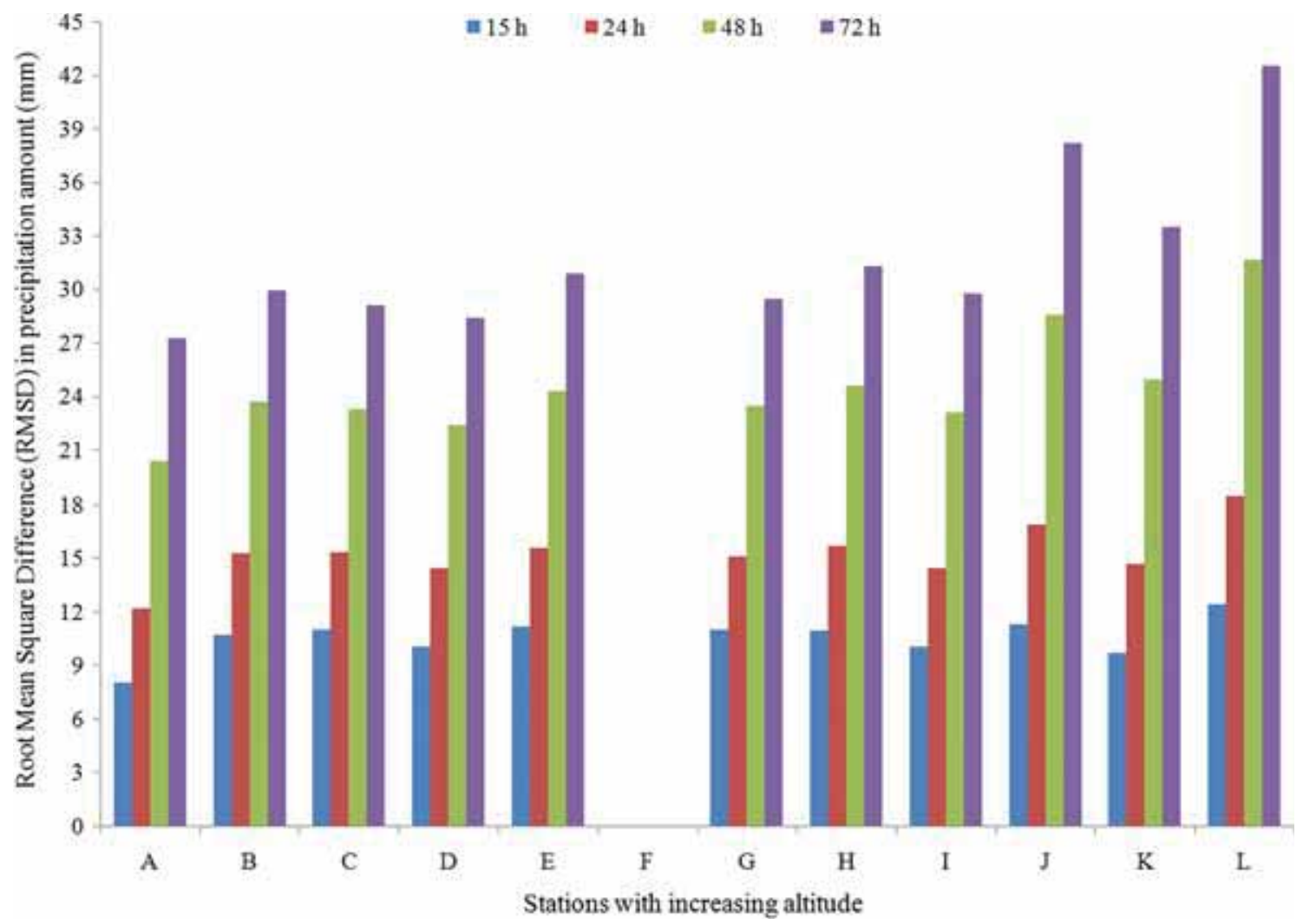

Figure 5. Root Mean Square Differences (RMSDs) in precipitation amounts of short time intervals (15-72 h) at 11 stations from a reference station, F, over the NWH.

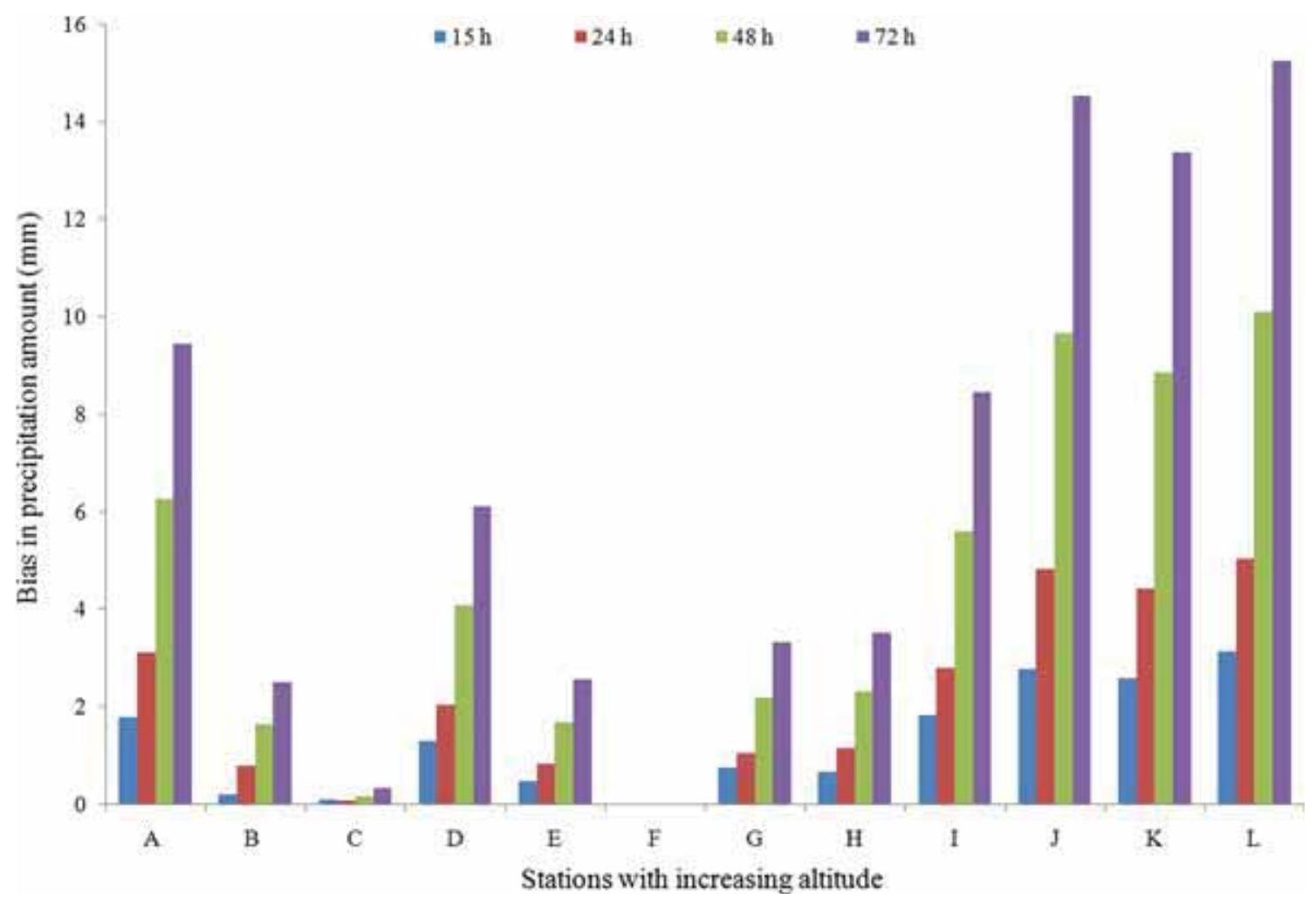

Figure 6. Biases (BIASes) in precipitation amounts of short time intervals $(15-72 \mathrm{~h})$ at different stations from a reference station, F, over the NWH. 
highlight need of short range local scale (site specific) weather forecasts over the NWH.

Mean biases of precipitation amounts of short time intervals at 11 stations from precipitation amount at a reference station, $\mathrm{F}$, fall in the range $0.1-3.1,0.1-5.0,0.2-10.1$ and $0.3-15.2 \mathrm{~mm}$ for 15 , 24, 48 and $72 \mathrm{~h}$ time intervals respectively (figure 6). Positive values of biases for precipitation amounts of short time intervals at 11 stations show that precipitation amount at a reference station, F, over estimates precipitation amount at 11 other stations over the NWH (figure 6). Biases of precipitation amounts of short time intervals at 11 stations increase as the length of short time interval increases (figure 6). This shows that precipitation amount of shorter time intervals $(24 \mathrm{~h}$ or less) at a reference station, $\mathrm{F}$, is better representative of precipitation amount at other 11 stations in the NWH compared to precipitation amount of longer time intervals.

\section{Conclusions and limitations}

Data on the precipitation amounts of short time intervals $(15,24,48$, and $72 \mathrm{~h})$ at 12 stations are analysed to gain an insight into and an understanding of the Spatio-temporal variability of binary weather patterns (precipitation event/no precipitation event) and precipitation amount over the NWH. The precipitation amounts of short time intervals at 12 stations were found to exhibit statistically significant CCs. However, the CCs do not provide any insight into the Spatiotemporal variability of binary weather patterns and the precipitation amounts of short time intervals. Binary weather patterns and the precipitation amounts of short time intervals are found to exhibit a large Spatio-temporal variability over the NWH. Binary weather patterns were found to differ maximum for a $24 \mathrm{~h}$ time interval at 12 stations in the NWH and the precipitation amounts of shorter time intervals (less than $24 \mathrm{~h}$ ) were found to differ minimum at 12 stations in the NWH. Hence the precipitation amount of a shorter time interval at one station can be a better estimator of the precipitation amount at any other station over the NWH.

Binary weather patterns and precipitation amounts of short time intervals are found to exhibit large Spatio-temporal variability at stations falling within the similar geographic areas in the NWH. This study provides a simple statistical mean to examine the Spatio-temporal variability of binary weather patterns and precipitation amounts of short time intervals based on precipitation data from the sparse meteorological observational network over the NWH. The results of this study can be used for the delineation of weather forecast areas, weather forecasting and expanding observational network, etc., over the NWH. The findings of this study highlight the need for short-range local-scale (site-specific) weather forecasts over the NWH.

This study is based on the precipitation data of short length (3377 days) at 12 stations sparsely distributed over the NWH. The binary classification of weather patterns (precipitation event/no precipitating event) is used to examine the Spatio-temporal variability of weather patterns of short time intervals (15-72 h) over the NWH. However, a similar study on long length precipitation data from a spatially homogeneous dense observational network over the NWH in future may provide better insight into the Spatio-temporal variability of binary weather patterns and precipitation amounts of short time intervals. Moreover, a comparison of this study with satellite-derived precipitation will be useful for a future study.

\section{Acknowledgements}

The authors are thankful to Shri Naresh Gupta, Director, Snow and Avalanche Study Establishment (SASE), for his constant encouragement during this study. The sincere efforts of the Scientists and Technical Staff of SASE, India, who collected data under the harsh climatic conditions of the NWH are gratefully acknowledged. The authors are also thankful to the anonymous reviewers whose comments helped to improve the quality of the manuscript.

\section{References}

Archer D R and Fowler H J 2004 Spatial and temporal variations in precipitation in the Upper Indus basin, global teleconnections and hydrological implications; Hydrol. Earth Syst. Sci. 8 47-61.

Arora M, Singh P, Goel N K and Singh R D 2006 Spatial distribution and seasonal variability of rainfall in a mountainous basin in the Himalayan region; Water Resour. Manag. 20 489-508.

Bhutiyani M R, Kale V S and Pawar N J 2008 Changing streamflow patterns in the rivers of northwestern Himalaya: Implications of global warming in the 20th century; Curr. Sci. 95 618-626. 
Bhutiyani M R, Kale V S and Pawar N J 2009 Climate change and the precipitation variations in the northwestern Himalaya: 1866-2006; Int. J. Clim. 30 535-548.

Das S, Singh S V, Rajagopal E N and Gall R 2003 Mesoscale modeling for mountain weather forecasting over the Himalayas; Bull. Am. Meteorol. Soc. 84 1237-1244.

Das T, Bárdossy A and Zehe E 2006 Influence of spatial variability of precipitation in a distributed rainfall-runoff model; In: Predictions in ungauged basins: Promise and

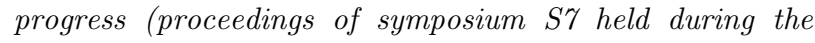
seventh IAHS scientific assembly at Foz do Iguacu, Brazil, April 2005), IAHS Publ, Vol. 303, pp. 195-203.

Dimri A P and Das S K 2006 Winter temperature and precipitation trends in the Siachen glacier; Curr. Sci. 98 1620-1625.

Dimri A P and Das S K 2011 Wintertime climatic trends in the western Himalayas; Clim. Chang. 111 775-800.

Dimri A P and Mohanty U C 1999 Snowfall statistics of some SASE field stations in J\&K; Def. Sci. J. 49 437-445.

Fowler H J and Archer D R 2005 Hydro-climatological variability in the Upper Indus basin and implications for water resources; In: Regional hydrological impacts of climatic change - Impact assessment and decision making (proceedings of symposium S6 held during the seventh IAHS scientific assembly at Foz do Iguacu, Brazil, April 2005), IAHS Publ, Vol. 295, pp. 131-138.

Hatwar H R, Yadav B P and Rama Rao Y V 2005 Prediction of Western disturbances and associated weather over Western Himalayas; Curr. Sci. 88 913-920.

Joshi J C and Srivastava S 2014 A hidden Markov model for avalanche forecasting on Chowkibal-Tangdhar road axis in Indian Himalayas; J. Earth Syst. Sci. 123 1771-1779.

Lang T J and Barros A P 2004 Winter storms in the Central Himalayas; J. Meteor. Soc. Japan 82 829-844.

Negi H S, Kanda N, Shekhar M S and Ganju A 2018 Recent wintertime climatic variability over the North West Himalayan cryosphere; Curr. Sci. 114 760-770.

Rangachary N and Bandyopadhyay B K 1987 An analysis of the synoptic weather pattern associated with extensive avalanching in Western Himalaya; In: Avalanche formation, movement and effects (proceedings of the Davos symposium, September 1986), IAHS Publ., Vol. 162, pp. 311-316.

Shekhar M S, Chand H, Kumar S, Srinivasan K and Ganju A 2010 Climate-change studies in the western Himalaya; Ann. Glacio. 51 105-112.

Singh D and Ganju A 2005 Expert system for prediction of avalanches; Curr. Sci. 94 1076-1081.

Singh D, Sharma V and Juyal V 2015 Observed linear trend in few surface weather elements over the Northwest Himalayas (NWH) during winter season; J. Earth Syst. Sci. 124 553-565.

Singh D, Sharma V and Juyal V 2016 Consistent seasonal snow cover depth and duration variability over the Western Himalayas (WH); J. Earth Syst. Sci. 125 1451-1461.

Srinivasan K, Ganju A and Sharma S S 2005 Usefulness of meso-scale weather forecast for avalanche forecasting; Curr. Sci. 88 921-926.

Srivastava G P 2006 Percentile data analysis of snowfall in J\&K and Siachen glaciers region; Def. Sci. J. 56 569-576.

Corresponding editor: KAVIRAJAN RAJENDRAN 